\title{
Plant Extract Assisted Green Synthesis and Structural Studies of Spinel Nial2o4 Nano-Catalysts
}

\author{
Govindaswamy Padmapriya, Pandian Paulraj, Ayyar Manikandan'
}

\begin{abstract}
Spinel NiAl2O4 nanoparticles were synthesized via Aloe vera plant extract microwave heating method. Aloe vera plant extract-assisted combustion method makes straightforward synthesis, which is alternative process of spinel preparation. The synthesized spinel NiAl2O4 nanoparticles was successfully characterized by powder XRD pattern, FT-IR, EDX analysis, HR-SEM analysis, and VSM techniques. XRD, FT-IR and EDS results established the development of spinel and single cubic phase NiAl2O4 nanocrystals. The formation of spherical shaped nanoparticles was affirmed by HR-SEM technique. VSM measurements revealed that NiAl2O4 sample have superparamagnetic behavior.
\end{abstract}

Keywords: Spinel NiAl204; Nanoparticles; Aloe vera extract; Magnetic properties;

\section{INTRODUCTION}

Recently, nanostructured spinel type materials are attractive in materials science and nanotechnology, for the reason that of their novel physical, chemical and catalytic activities than that of their same bulkiness materials [1-5]. Among the various spinel materials, Nickel aluminate (NiAl2O4), has gained much attention in interdisciplinary areas due to their high mechanical strength, and chemical stability [6-8]. Various synthesis routes have been used to prepare the spinel type nanomaterials [8-10]. But the methods have some disadvantageous such as costly equipments and materials and difficult synthetic procedures. Recently, a facile microwave combustion method (MCM) has been used. In this route, the nanomaterials are synthesized at lower temperatures and also enough low cost with good controlled size of the products [10-12].

The present work focused on the synthesis of spinel NiAl2O4 nanoparticles by using green method on extract from Aloe vera microwave combustion method. Aloe vera is a permanent juicy belonging to the Liliaceal family [13-17]. To our knowledge, no literature is available on the synthesis of NiAl2O4 nanostructures by Aloe vera plant extract microwave heating method. Nevertheless, Aloe vera plant extracts using as the reducing agent by microwave heating method. Moreover, spinel NiAl2O4 nanomaterials are non-toxic, inexpensive, comparatively higher surface area

Revised Manuscript Received on December 11, 2019

Govindaswamy Padmapriya Department Of Science \& Humanities, Bharath Institute Of Higher Education And Research TamilNadu,India.Email: ppstminex@gmail.com

Pandian Paulraj, Assistant Professor, Department Of Science \& Humanities, Bharath Institute Of Higher Education And Research TamilNadu,India.Email: paulrajp.che@bharathuniv.ac.in

Ayyar Manikandan Department Of Science \& Humanities, Bharath Institute Of Higher Education And Research TamilNadu,India.Email: mkavath15@gmail.com and the properties formulate them proper for use as inexpensively feasible nano-catalysts [18-28]

\section{EXPERIMENTAL METHOD AND TECHNIQUES}

\section{A. Materials}

Nitrates of Nickel and aluminum, plant extract as the raw materials were used by this method. Millipore water was used for this synthesis. Aloe vera-extract was prepared from a $5 \mathrm{~g}$ piece of methodically washed leaves were thinly cut and the gel obtained was liquefied in $10 \mathrm{ml}$ of distilled $\mathrm{H} 2 \mathrm{O}$ and stirred for $30 \mathrm{~min}$, which is known as Aloe vera plant extract. [20-26]Nitrates of Nickel, and aluminum were dissolved in the plant extract under stirring for $1 \mathrm{~h}$ and then located in a domestic microwave oven for 10 mins. After completion of the reaction, the attained powders were labeled as $\mathrm{NiAl} 2 \mathrm{O} 4$

\section{B. Characterization}

The structural characterization of spinel $\mathrm{NiAl}_{2} \mathrm{O}_{4}$ nano-crystals were carry out using a Rigaku Ultima XRD $(\lambda=$ $1.5418 \AA$ ). The functional groups were analyzed by Elmer FT-IR. The morphology was achieve with a Joel JSM 6360 HR-SEM analysis. Magnetic properties were carried out 3900 model VSM.

\section{RESULTS AND DISCUSSION}

\section{A. XRD analysis}

The structure, crystallite size, phase formation of the powder were established by the XRD pattern. Fig. 1 shows the XRD of spinel NiAl2O4 nanoparticle. The peaks of 31.13, 36.84, $38.64,44.53,49.14,55.73,59.43,65.53,74.25$ and $77.52^{\circ}$ can be absolutely indexed as fcc spinel NiAl2O4 (JCPDS card no. 38-0814).

The crystallite size measured using Scherrer's Eq. $(1)$,

$$
D=\frac{0.89 \lambda}{\beta \cos \theta}
$$

The calculated crystallite size is $18.35 \mathrm{~nm}$.

\section{B. FT-IR analysis}

A wide-ranging band appeared in the expanse $3220-3440 \mathrm{~cm}^{-1}$ showed the vibrations of $\mathrm{H}_{2} \mathrm{O}$ (Fig. 2). A band at around $1630 \mathrm{~cm}^{-1}$ was assigned by $\mathrm{H}-\mathrm{O}-\mathrm{H}$ vibration. The band at $2357 \mathrm{~cm}^{-1}$ is due to the $\mathrm{CO}_{2}$ vibration. The $\mathrm{M}-\mathrm{O}$ stretching bands in the range $550-850 \mathrm{~cm}^{-1}$, connected to the $\mathrm{Al}-\mathrm{O}$ and $\mathrm{Ni}-\mathrm{O}-\mathrm{Al}[14,15]$. 


\section{SEM analyze}

Fig. 3 shows HR-SEM image of NiAl2O4 sample. HR-SEM image clearly shows the agglomerated particle-like nano-crystals. From the results, it is assumed the microwave heating process, the microwaves are involved for nucleation and formed the final products with narrow size range of particles within few minutes.

\section{VSM study}

The magnetization of NiAl2O4 nanoparticle was analyzed through external field between \pm 10 kOe by VSM at room temperature. Magnetization (M) versus applied field (H) curve is shown in Fig. 4. From the M-H curve, we can infer that a soft magnetic nature of NiAl2O4 material and also indicate superparamagnetism at $\pm 15 \mathrm{kOe}$. The obtained results show that the value of $\mathrm{Ms}$ is $1.45 \times 10-4 \mathrm{emu} / \mathrm{g}$. However, it is noted that lower $\mathrm{Ms}, \mathrm{Hc}$ and $\mathrm{Mr}$ values confirmed the NiAl2O4 nanoparticles have soft nature of superparamagnetism [16-23].

\section{Conclusions}

Spinel NiAl2O4 nano-catalysts were prepared by a easy microwave heating route using Aloe vera plant extract. The results of the prepared sample have a spinel. The manifestation of wide-ranging band between 550 and 850 $\mathrm{cm}-1$ exposed the arrangement of $\mathrm{Al}-\mathrm{O}$ and $\mathrm{Ni}-\mathrm{O}-\mathrm{Al}$ bond appearance. SEM image showed the construction of well residential particle with nano grains. VSM studies revealed that $\mathrm{NiAl} 2 \mathrm{O} 4$ showed superparamagnetism

\section{REFERENCES}

1. A. Manikandan, R. Sridhar, S. Arul Antony, S. Ramakrishna, A simple aloe vera plant-extracted microwave and conventional combustion synthesis: Morphological, optical and catalytic properties of magnetic $\mathrm{CoFe}_{2} \mathrm{O}_{4}$ nanostructures, Journal of Molecular Structure, 1076 (2014) 188-200.

2. A. Manikandan, M. Durka, K. Seevakan, S. Arul Antony, A novel one-pot combustion synthesis and opto-magnetic properties of magnetically separable spinel $\mathrm{Mn}_{x} \mathrm{Mg}_{1-x} \mathrm{Fe}_{2} \mathrm{O}_{4} \quad(0.0 \leq x \leq 0.5)$ nano-photocatalysts, Journal of Superconductivity and Novel Magnetism, 28 (2015) 1405-1416.

3. A. Manikandan, M. Durka, S. Arul Antony, One-pot flash combustion synthesis, structural, morphological and opto-magnetic properties of spinel $\mathrm{Mn}_{x} \mathrm{Co}_{1-x} \mathrm{Al}_{2} \mathrm{O}_{4}$ ( $x=0,0.3$ and 0.5 ) nano-catalysts, Journal of Superconductivity and Novel Magnetism, 28 (2015) 209-218.

4. A. Manikandan, M. Durka, S. Arul Antony, Hibiscus rosa-sinensis leaf extracted green methods, magneto-optical and catalytic properties of spinel $\mathrm{CuFe}_{2} \mathrm{O}_{4}$ nano- and microstructures, Journal of Inorganic and Organometallic Polymers and Materials, 25 (2015) 1019-1031.

5. A. Manikandan, M. Durka, S. Arul Antony, A novel synthesis, structural, morphological and opto-magnetic characterizations of magnetically separable spinel $\mathrm{Co}_{\mathrm{x}} \mathrm{Mn}_{1-\mathrm{x}} \mathrm{Fe}_{2} \mathrm{O}_{4}$ $(0 \leq \mathrm{x} \leq 1)$ nano-catalysts, Journal of Superconductivity and Novel Magnetism, 27 (2014) 2841-2857.

6. A. Manikandan, S. Arul Antony, R. Sridhar, M. Bououdina, A simple combustion synthesis and optical studies of magnetic $\mathrm{Zn}_{1-x} \mathrm{Ni}_{x} \mathrm{Fe}_{2} \mathrm{O}_{4}$ nanostructures for photoelectrochemical applications, Journal of Nanoscience and Nanotechnology, 15 (2015) 4948-4960.

7. A. Manikandan, M. Durka, S. Arul Antony, Magnetically recyclable spinel $\mathrm{Mn}_{\mathrm{x}} \mathrm{Zn}_{1-\mathrm{x}} \mathrm{Fe}_{2} \mathrm{O}_{4} ;(0.0 \leq \mathrm{x} \leq 0.5)$ nano-photocatalysts, Advanced Science, Engineering and Medicine, 7 (2015) 33-46.

8. A. Manikandan, E. Hema, M. Durka, K. Seevakan, T. Alagesan, S. Arul Antony, Room temperature ferromagnetism of magnetically recyclable photocatalyst of $\mathrm{Cu}_{1-\mathrm{x}} \mathrm{Mn}_{\mathrm{x}} \mathrm{Fe}_{2} \mathrm{O}_{4}-\mathrm{TiO}_{2}(0.0 \leq \mathrm{x} \leq 0.5)$ nano-composites, Journal of Superconductivity and Novel Magnetism, 28 (2015) 1783-1795.

9. A. Manikandan, M. Durka, S. Arul Antony, Role of $\mathrm{Mn}^{2+}$ doping on structural, morphological and opto-magnetic properties of spinel $\mathrm{Mn}_{\mathrm{x}} \mathrm{Co}_{1-\mathrm{x}} \mathrm{Fe}_{2} \mathrm{O}_{4}(x=0.0,0.1,0.2,0.3,0.4$ and 0.5$)$ nano-catalysts,

Journal of Superconductivity and Novel Magnetism, 28 (2015) 2047-2058

10. M. F. Valan, A. Manikandan, S. Arul Antony, Microwave combustion synthesis and characterization studies of magnetic $\mathrm{Zn}_{1-x} \mathrm{Cd}_{x} \mathrm{Fe}_{2} \mathrm{O}_{4}(0 \leq x$ $\leq 0.5$ ) nanoparticles, Journal of Nanoscience and Nanotechnology, 15 (2015) 4543-4551.

11. E. Hema, A. Manikandan, S. Suganya, M. Durka, S. Arul Antony, B. R Venkatraman,

A novel synthesis of $\mathrm{Zn}^{2+}$-doped $\mathrm{CoFe}_{2} \mathrm{O}_{4}$ spinel nanoparticles: Structural, morphological, opto-magnetic and catalytic properties, Journal of Superconductivity and Novel Magnetism, 28, 8 (2015) 2539-2552.

12. S. Jayasree, A. Manikandan, A. M. Uduman Mohideen, C. Barathiraja, E. Hema, S. Arul Antony, Comparative study of combustion methods, opto-magnetic and catalytic properties of spinel $\mathrm{CoAl}_{2} \mathrm{O}_{4}$ nano- and microstructures, Advanced Science, Engineering and Medicine, 7 , (2015) 672-682.

13. A. Manikandan, M. Durka, M. Amuth Selvi, S. Arul Antony, Aloe vera plant extracted green synthesis, structural and opto-magnetic characterizations $\quad$ of spinel $\mathrm{Co}_{\mathrm{x}} \mathrm{Zn}_{1-x} \mathrm{Al}_{2} \mathrm{O}_{4}$ nano-catalysts, Journal of Nanoscience and Nanotechnology, 16 (2016) 357-373

14. A. Mary Jacintha, A. Manikandan, K. Chinnaraj, S. Arul Antony, P. Neeraja, Comparative studies of spinel $\mathrm{MnFe}_{2} \mathrm{O}_{4}$ nanostructures: Structural, morphological, optical, magnetic and catalytic properties, Journal of Nanoscience and Nanotechnology, 15 (2015) 9732-9740.

15. A. Manikandan, M. Durka, M. Autha Selvi, S. Arul Antony, Sesamum indicum plant extracted microwave combustion synthesis and opto-magnetic properties of spinel $\mathrm{Mn}_{\mathrm{x}} \mathrm{Co}_{1-\mathrm{x}} \mathrm{Al}_{2} \mathrm{O}_{4}$ nano-catalysts, Journal of Nanoscience and Nanotechnology, 16 (2016) 448-456.

16. P. Paulraj, N. Janaki, S. Sandhya, K. Pandian, Single pot synthesis of polyaniline protected silver nanoparticles by interfacial polymerization and study its application on electrochemical oxidation of hydrazine Colloids and Surfaces A: Physicochem. Eng. Aspects 377 (2011) 28-34

17. A. Manikandan, A. Saravanan, S. Arul Antony, M. Bououdina, One-pot low temperature synthesis and characterization studies of nanocrystalline $\alpha-\mathrm{Fe}_{2} \mathrm{O}_{3}$ based dye sensitized solar cells, Journal of Nanoscience and Nanotechnology, 15 (2015) 4358-4366.

18. A. Manikandan, S. Arul Antony, A novel approach for the synthesis and characterization studies of $\mathrm{Mn}^{2+}$ doped CdS nano-crystals by a facile microwave combustion method, Journal of Superconductivity and Novel Magnetism, 27 (2014) 2725-2733.

19. R. Marx Nirmal, P. Paulraj, K. Pandian, K. Sivakumar, Preparation, Characterization and Photocatalytic Properties of CdS and Cd1-xZnxS nanostructures, AIP Conf. Proc. 1391 (2011) 597-599.

20. A. Manikandan, M. Durka, S. Arul Antony, $\mathrm{Mn}^{2+}$ doped NiS $\left(\mathrm{Mn}_{x} \mathrm{Ni}_{1-x} \mathrm{~S}\right.$ : $x=0.0,0.3$ and 0.5$)$ nanocrystals: Structural, morphological opto-magnetic and photocatalytic properties, Journal of Inorganic and Organometallic Polymers and Materials, 25 (2015) 804-815.

21. E. Prabakaran, S. Parani, M. Alexander, P. Paulraj, K. Pandian, Synthesis of chitosan oligomer stabilized silver nanorod and its modified glassy carbon electrode for reduction of chlorophenols, J. Nanosci. Lett. 3 (2013) 18(1-9).

22. K. Chinnaraj, A. Manikandan, P. Ramu, S. Arul Antony, P. Neeraja, Comparative study of microwave and sol-gel assisted combustion methods of $\mathrm{Fe}_{3} \mathrm{O}_{4}$ nanostructures: Structural, morphological, optical, magnetic and catalytic properties, Journal of Superconductivity and Novel Magnetism, 28 (2015) 179-190.

23. M. F. Valan, A. Manikandan, S. Arul Antony, A novel synthesis and characterization studies of magnetic $\mathrm{Co}_{3} \mathrm{O}_{4}$ nanoparticles, Journal of Nanoscience and Nanotechnology, 15 (2015) 4580-4586.

24. K. Kaviyarasu, E. Manikandan, P. Paulraj, S.B. Mohamed, J. Kennedy, One dimensional well-aligned $\mathrm{CdO}$ nanocrystal by solvothermal method, Journal of Alloys and Compounds 593 (2014) 67-70.

25. E. Hema, A. Manikandan, S. Suganya, M. Durka, S. Arul Antony, B. R. Venkatraman,

A novel synthesis of $\mathrm{Zn}^{2+}$-doped $\mathrm{CoFe}_{2} \mathrm{O}_{4}$ spinel nanoparticles: Structural, morphological, opto-magnetic and catalytic properties, Journal of Superconductivity and Novel Magnetism, 28, 8 (2015) 2539-2552.

26. P. Paulraj, A. Manikandan, E. Manikandan, K. Pandian, M. K. Moodley, K. Roro, and K. Murugan, Solid-State Synthesis of POPD@AgNPs Nanocomposites for Electrochemical Sensors, J. Nanosci. Nanotechnol. 18 (2018) 3991-3999.

27. D. K. Manimegalai, A. Manikandan, S. Moortheswaran, S. Arul Antony, Magneto-Optical and Photocatalytic Properties of Magnetically Recyclable $\mathrm{Zn}_{1-x} \mathrm{Mn}_{x} \mathrm{~S}(x=0.0,0.3$ and 0.5) nano-catalysts, Journal of 
Superconductivity and Novel Magnetism, 28, 9, (2015) 2755-2766

28. P. Bhavani, A. Manikandan, P. Paulraj, A. Dinesh, M. Durka, S. Arul Antony, Okra (Abelmoschus esculentus) Plant Extract-Assisted Combustion Synthesis and Characterization Studies of Spinel $\mathrm{ZnAl}_{2} \mathrm{O}_{4}$ Nano-Catalysts, J. Nanosci. Nanotechnol. 18 (2018) 4072-4081.

\section{AUTHORS PROFILE}

Govindaswamy Padmapriya Associate Professor Department Of Science \& Humanities, Bharath Institute Of Higher Education And Research TamilNadu,India

Pandian Paulraj, Associate Professor, Department Of Science \& Humanities, Bharath Institute Of Higher Education And Research TamilNadu,India

Ayyar Manikandan Associate Professor Department Of Science \& Humanities, Bharath Institute Of Higher Education And Research TamilNadu,India 